HELMINTHOLOGIA, 54, 3: 225 - 230, 2017

\title{
Preimaginal mortality of Musca domestica (Diptera: Muscidae) due to Habronema muscae (Nematoda: Habronematidae)
}

\author{
R. K. SCHUSTER
}

Central Veterinary Research Laboratory, PO Box 597, Dubai, United Arab Emirates, E-mail: rschuster@cvrl.ae

Article info

Received December 29, 2016 Accepted April 24, 2017

\begin{abstract}
Summary
In order to study the damage of Habronema muscae (Carter, 1861) on its intermediate host, Musca domestica Linnaeus, 1758, fly larval feeding experiments were carried out. For this, a defined number of praeimaginal stages of $M$. domestica was transferred in daily intervals (from day 0 to day 10) on faecal samples of a naturally infected horse harboring 269 adult $H$. muscae in its stomach. The development of $M$. domestica was monitored until imagines appeared. Harvested pupae were measured and weighted and the success of infection was studied by counting $3^{\text {rd }}$ stage nematode larvae in freshly hatched flies. In addition, time of pupation and duration of the whole development of the flies was noticed. Pupation, hatching and preimaginal mortality rates were calculated and the number of nematode larvae in freshly hatched flies was counted. Adult flies harboured up to 60 Habronema larvae. Lower pupal volumes and weights, lower pupation rates and higher preimaginal mortality rates were found in experimental groups with long exposure to parasite eggs compared to experimental groups with short exposure or to the uninfected control groups. Maggots of the former groups pupated earlier and fly imagines occurred earlier. These findings clearly showed a negative impact of $H$. muscae on the development of $M$. domestica. The results are discussed in connection with the destruction of adipose cells in the maggots by developing nematode larvae.
\end{abstract}

Keywords: Habronema muscae; Musca domestica; larval development; parasite host interaction

\section{Introduction}

Equine stomach worms of the family habronematidae have a wide geographical distribution. While aberrant larvae of these parasites cause conspicuous cutaneous and conjunctival alterations (summer sores) gastric habronematidosis remains usually unrecognized and its clinical significance is underestimated.

Although the life cycle with muscid flies acting as intermediate hosts and vectors has been disclosed a century ago (Ransom, 1911; Johnston, 1913; Hill, 1918; Johnston \& Bancroft, 1920; Roubaud \& Descazeaux, 1921; Roubaud \& Descazeaux, 1922), little is known about the impact of parasite larval stages on their avertebrate intermediate hosts.
Previous experimental infections (Schuster \& Sivakumar, 2016) of Musca domestica Linnaeus, 1758 larvae with Habronema muscae (Carter, 1861) gave first indication that the infection influences pupal sizes and increases the mortality rate of preimaginal stages of houseflies. It was noticed that pupae of the uninfected control group were smaller compared to those of the experimental group where the insects spent their entire larval development in a dung sample of naturally infected horse. While in the control group $82.0 \%$ of fly eggs developed into imagines this rate decreased to $27.0 \%$ in the experimental group.

The purpose for this study was to investigate the influence of rising expositions of housefly larvae to $H$. muscae eggs on pupation rate, size of pupae and total mortality of preimaginal stages of $M$. do- 
mestica for a better understanding of damages caused to avertebrate hosts by parasites.

\section{Materials and Methods}

\section{Musca domestica}

A housefly strain consisting of $300-500$ individuals kept in a screen cage under laboratory conditions at $24-30{ }^{\circ} \mathrm{C}, 60 \%$ relative humidity and light cycle $12: 12 \mathrm{~h}$ (light : dark) was the basis of our experiment. The strain originated from 50 houseflies captured at a camel milk farm (Emirates Industry for Camel Milk Products) in Dubai in 2012. The morphology of the carefully selected insects and their development stages matched the description of $M$. domestica by Hewitt (1910) and Skidmore (1985). Adult flies were fed with a mixture of wetted milk powder (Aptamil囚) and sucrose (2:1). A cylinder with moist filter paper served as drinker. The parasite free medium for rearing fly larvae consisted of a moist mixture of wheat bran and alfalfa hay powder (9:1).

\section{Habronema muscae}

Adults of $H$. muscae in numbers of 112 male and 157 female stomach worms was a secondary finding in a horse necropsied in July 2016. Pieces of dung taken from the rectum in aliquots of 30 $\mathrm{g}$ were put into glass cylinders, covered with parafilm and stored until use for up to 10 days at $4{ }^{\circ} \mathrm{C}$ in the refrigerator.

\section{Experimental design}

Housefly eggs were harvested by putting an open $90 \mathrm{~mm}$ Petri dish filled with larval rearing medium into the screen cage. After $5 \mathrm{~h}$ the dish was removed and checked for the presence of fly eggs. The mixture of larval rearing medium and Musca eggs was then transferred into in a large glass Petri dish (diameter: 200 $\mathrm{mm}$ ) at a constant temperature of $26^{\circ} \mathrm{C}$. At day 0,100 eggs were transferred directly from the larval rearing medium onto the first dung sample (substrate) of the naturally $H$. muscae infected horse (group D0). At day 1, $1001^{\text {st }}$ Musca instars were collected from the rearing medium and were transferred onto the next faecal sample (group D1). From day 2 to day 10 each 50 fly larvae were used (groups D2 - D10). Two uninfected control groups starting with 50 fly eggs each were reared on a sample of larval rearing medium (group KO medium) and on faeces of an uninfected horse (group K0 faeces), respectively. To avoid contamination all glass cylinders were kept in plastic containers covered with paper tissue secured by rubber rings and were stored at $26^{\circ} \mathrm{C}$. Depending on food consumption of the growing larvae of experimental groups further dung pieces of the infected horse were added. At the end of their larval development maggots started to leave the breeding substrate to pupate. Starting at day 6 containers were checked for the presence of pupae. Remaining fly larvae were put back into the substrate and the examination was repeated the following days.

To establish the average weight, all pupae that were present at the second day of pupation were put on a laboratory scale and their total weight was divided by number of pupae. For all individual pupae in each group length and width was measured under a stereoscopic microscope. Since the geometrical shape of fly pupae are close to an elongated ellipsoid (prolate or spheroid) their approximate volume can be calculated best by the formula: $\mathrm{V}=$ $4^{*} \pi / 3^{*} a^{2 *} c=4.19 a^{2} c$, where $a$ and $c$ are half of length and half of width of the pupae, respectively.

\section{Examination of flies}

For the examination of flies, the following protocol by Schuster and Sivakumar $(1913,2017)$ was used. In brief, hatched fly imagines were separated within $12 \mathrm{~h}$ after emergence, immobilized by cold $\left(-18^{\circ} \mathrm{C}\right.$ for $5 \mathrm{~min}$.), sorted by sex and dissected. Caput, thorax and abdomen were put separately into drops of water on glass slides, were dismembered by preparation needles and checked for the presence of nematode larvae under a stereoscopic microscope. Prior to examination, the slides were put for 10 min on a heated plate $\left(40{ }^{\circ} \mathrm{C}\right)$ to stimulate the movement of Habronema larvae to actively to leave the tissues of the flies. The slides were then put for 5 min on an ice pack to slow down the active movement for a better counting. The separate examination of caput, thorax and abdomen was primarily done to determine the larval burden of the parasite more exactly.

\section{Statistical treatment of the data}

Prevalence and mean intensity of Habronema larvae in fly imagines at their $95 \%$ confidence intervals were calculated using the software package Quantitative Parasitology 3.0 (QP WEB) (Rozsa et al., 2000). The same software was applied to calculate average and $95 \%$ confidence intervals for pupation and total survival rates as well as for the pupal volumes.

\begin{tabular}{lccc}
\multicolumn{4}{c}{$\begin{array}{c}\text { Table 1. Time of larval pupation and fly hatching of } \\
\text { under various exposure of their larvae to Habronema muscae eggs. }\end{array}$} \\
\hline Group & $\begin{array}{c}\text { Average } \\
\text { exposure } \\
\text { (d) }\end{array}$ & $\begin{array}{c}\text { Pupation } \\
\text { (d post oviposition) }\end{array}$ & $\begin{array}{c}\text { Hatching } \\
\text { (d post oviposition) }\end{array}$ \\
\hline D0 & 8.5 & $7-10$ & $11-14$ \\
D1 & 7.5 & $7-10$ & $13-14$ \\
D2 & 6.5 & $7-10$ & $11-13$ \\
D3 & 5.5 & $7-10$ & $12-15$ \\
D4 & 6 & $9-11$ & $12-13$ \\
D5 & 4 & $8-10$ & $13-14$ \\
D6 & 3 & $8-10$ & $15-16$ \\
D7 & 2 & $8-10$ & $14-15$ \\
D8 & 3.5 & $10-13$ & $14-18$ \\
D9 & 3 & $11-13$ & $16-21$ \\
D10 & 2 & $11-13$ & $17-22$ \\
K0medium & 0 & $11-13$ & $17-20$ \\
k0faeces & 0 & $10-13$ & $14-17$ \\
\hline
\end{tabular}


Table 2. Development of Musca domestica, larvae of which were exposed to Habronema muscae eggs in comparison to uninfected controls (K0). Figures in brackets show the $95 \%$ confidence intervals. ( ${ }^{*}$ these samples were inoculated with Musca eggs).

\begin{tabular}{|c|c|c|c|c|c|c|}
\hline Group & $\begin{array}{c}\text { Larvae } \\
\text { used } \\
\text { (n) }\end{array}$ & $\begin{array}{c}\text { Pupae } \\
\text { developed } \\
\text { (n) }\end{array}$ & $\begin{array}{l}\text { Pupation rate } \\
\text { (\%) }\end{array}$ & $\begin{array}{c}\text { Flies hatched } \\
\text { (n) }\end{array}$ & $\begin{array}{l}\text { Hatching rate } \\
(\%)\end{array}$ & $\begin{array}{l}\text { Preimaginal mortality rate } \\
\qquad(\%)\end{array}$ \\
\hline D0 & $100^{*}$ & 44 & $\begin{array}{c}44.0 \\
<34.1 ; 54.3>\end{array}$ & 37 & 84.1 & $\begin{array}{c}63.0 \\
<52.8 ; 72.4>\end{array}$ \\
\hline D1 & 100 & 45 & $\begin{array}{c}45.0 \\
<35.0 ; 55.3>\end{array}$ & 38 & 84.4 & $\begin{array}{c}62.0 \\
<51.7 ; 71.5>\end{array}$ \\
\hline D2 & 50 & 24 & $\begin{array}{c}48.0 \\
<33.7 ; 62.6>\end{array}$ & 24 & 100.0 & $\begin{array}{c}52.0 \\
<337.4 ; 66.3>\end{array}$ \\
\hline D3 & 50 & 26 & $\begin{array}{c}52.0 \\
<37.4 ; 66.3>\end{array}$ & 22 & 84.6 & $\begin{array}{c}56.0 \\
<41.3 ; 70.0>\end{array}$ \\
\hline D4 & 50 & 33 & $\begin{array}{c}66.0 \\
<51.2 ; 78.8>\end{array}$ & 33 & 100.0 & $\begin{array}{c}34.0 \\
<21.2 ; 48.8>\end{array}$ \\
\hline D5 & 50 & 38 & $\begin{array}{c}76.0 \\
<61.8 ; 86.9>\end{array}$ & 36 & 94.7 & $\begin{array}{c}28.0 \\
<16.2 ; 42.5>\end{array}$ \\
\hline D6 & 50 & 39 & $\begin{array}{c}78.0 \\
<64.0 ; 88.5>\end{array}$ & 30 & 76.9 & $\begin{array}{c}40.0 \\
<26.4 ; 54.8>\end{array}$ \\
\hline D7 & 50 & 43 & $\begin{array}{c}86.0 \\
<73.3 ; 94.2>\end{array}$ & 41 & 95.3 & $\begin{array}{c}18.0 \\
<8.6 ; 31.4>\end{array}$ \\
\hline D8 & 50 & 45 & $\begin{array}{c}90.0 \\
<78.2 ; 96.7>\end{array}$ & 40 & 88.9 & $\begin{array}{c}20.0 \\
<10.0 ; 33.7>\end{array}$ \\
\hline D9 & 50 & 45 & $\begin{array}{c}90.0 \\
<78.2 ; 96.7>\end{array}$ & 37 & 82.2 & $\begin{array}{c}26.0 \\
<14.6 ; 40.3>\end{array}$ \\
\hline D10 & 50 & 47 & $\begin{array}{c}94.0 \\
<83.5 ; 98.7>\end{array}$ & 41 & 87.2 & $\begin{array}{c}18.0 \\
<8.6 ; 31.4>\end{array}$ \\
\hline KOmedium & $50^{*}$ & 42 & $\begin{array}{c}84.0 \\
<70.9 ; 92.8>\end{array}$ & 41 & 97.6 & $\begin{array}{c}18.0 \\
<8.6 ; 31.4>\end{array}$ \\
\hline KOfaeces & $50^{*}$ & 41 & $\begin{array}{c}82.0 \\
<68.6 ; 91.4> \\
\end{array}$ & 39 & 95.1 & $\begin{array}{c}22.0 \\
<11.5 ; 31.4> \\
\end{array}$ \\
\hline
\end{tabular}

\section{Results}

Most of the fly larvae left the substrate prior to pupation and pupae were found on the ground of the plastic container harboring the glass cylinder containing the substrate. These larvae had stopped eating and pupated within $12 \mathrm{~h}$. Pupation in experimental groups with the longest exposure (D0, D1, D2, D3) started already at day 7 and was completed at day 10 after oviposition. Fly imagines in these groups started to occur between day 11 and day 13. Contrary to this, in groups with short exposure $(\mathrm{D} 8, \mathrm{D} 9, \mathrm{D} 10)$ or in the uninfected control groups ( $\mathrm{K} 0$ medium, $\mathrm{K} 0$ faeces) pupation started at day 10 and was completed at day 13 while first flies emerged between day 14 to day 17 (Table 1). As seen from Table 2, pupation rate rose from $44 \%$ in the group with the longest exposition (D0) to more than $80 \%$ in short time exposed (D7, D8, D9, D10) and uninfected control groups (K0 medium, K0 faeces). There was a significant difference in the pupation rate and in the total preimaginal mortality between the groups of the longest exposure (D0, $D 1, D 2$ and D3) and those groups with the shortest exposure (D7, D8, D9, D10) while the hatching rate varied between $76.9 \%$ in group D6 and $100 \%$ in groups D2 and D4.

Pupae in the different groups had different volumes and weights.
Smallest pupae of lengths below $5 \mathrm{~mm}$ and width smaller $2 \mathrm{~mm}$ and a subsequent volume of less than $10.4 \mathrm{~mm}^{3}$ were present in groups D0 to D5. Average pupal volumes in these groups varied between 15.3 and $22.9 \mathrm{~mm}^{3}$ and their average weight was 13 to 19 $\mathrm{mg}$. Contrary to this, the largest pupae measuring more than $8 \mathrm{~mm}$ in length and more than $2.9 \mathrm{~mm}$ in width with a subsequent volume of more than $35 \mathrm{~mm}^{3}$ were present in the groups with the shortest exposure (D9 and D10) and in the uninfected control group KOmedium. The averages pupal volumes in these groups were above $30 \mathrm{~mm}^{3}$. The average pupal weight equaled to $24-26 \mathrm{mg}$. Pupae larvae of which developed in faeces of an uninfected horse (KOfaeces) were slightly smaller and lighter (Table 3).

All hatched flies in groups D0 - D6 were infected with Habronema larvae (Table 4). The average larval burden in these groups varied between 19.7 in group D6 and 29.7 in group D0. The larval prevalence in group D7 was still $90.2 \%$ but larval burden dropped sharply to 3.2. The infection rate in groups D8 and D9 fell further to 50,0 and $13.5 \%$ with an average larval burdens of only 3.4 and 2.0, respectively. In group D10 only one out of 41 flies were infected with two larvae. The maximum number of Habronema larvae found in freshly hatched flies was 60 in a fly in group D1. 
Table 3. Average pupal weight and volume of experimentally infected Musca domestica with different exposition of their larvae to Habronema muscae eggs. Figures in brackets show the $95 \%$ confidence intervals.

\begin{tabular}{lccc}
\hline & & \multicolumn{2}{c}{ Average } \\
\cline { 3 - 4 } Group & Exposure $(\mathrm{d})$ & Weight $(\mathrm{mg})$ & Volume $\left(\mathrm{mm}^{3}\right)$ \\
\hline D0 & 8.5 & 16 & $19.4<18.6 ; 20.4>$ \\
D1 & 7.5 & 16 & $17.0<15.0 ; 18.3>$ \\
D2 & 6.5 & 18 & $20.6<18.4 ; 23.0>$ \\
D3 & 5.5 & 13 & $15.3<13.0 ; 16.7>$ \\
D4 & 6 & 15 & $22.9<20.7: 24.4>$ \\
D5 & 4 & 19 & $20.7<19.1 ; 21.9>$ \\
D6 & 3 & 19 & $23.8<22.1 ; 25.2>$ \\
D7 & 2 & 19 & $25.1<23.6 ; 26.8>$ \\
D8 & 3.5 & 23 & $25.7<23.6 ; 27.2>$ \\
D9 & 3 & 24 & $31.2<29.6 ; 32.6>$ \\
D10 & 2 & 26 & $31.0<29.5 ; 32.2>$ \\
K0medium & 0 & 26 & $30.3<28.7 ; 32.0>$ \\
K0faeces & 0 & 24 & $25.5<24.7 ; 26.3>$ \\
\hline
\end{tabular}

\section{Discussion}

Compared to other nematode infections of equids habronematidosis is only marginally investigated. The main obstacle is the fact that eggs of habronematids cannot be demonstrated in routine diagnostic procedures and our knowledge about the occurrence of these nematodes is mainly based on necropsy results. Claims on efficacy of anthelminthics against these nematodes are based on findings of habronematids in untreated control animals and their absence in treated experimental groups. The principle involvement of houseflies in the life cycle of $H$. muscae is known more than 100 years ago but detailed examinations how the parasite influence the larval development of houseflies are rare.

Horse faeces were reported to be a good breeding substrate for houseflies in most of the early observations on the life cycle of this insect (Howard, 1898; Leikina, 1943) while other sources showed a poor development of fly larvae in horse manure (Larrain \& Salas, 2008; Machtinger, 2011). Hewitt (1910) concluded that larvae of $M$. domestica can develop in all kind of decaying animal or vegetable matter when fermentation is occurring and the development time depends on quality of the food, temperature and moisture. In our experiments where Musca larvae were reared under constant temperature conditions flies from experimental groups with the longest exposure to Habronema eggs developed quicker compared to those in groups with a short or without exposure.

The parasitism of $H$. muscae influenced size and weight of housefly pupae. Unfortunately, there are only few observations on these parameters to compare with. Average length of housefly pupae was in a range of $6-8 \mathrm{~mm}$ (Karandikar \& Ranade, 1965; Zumpt, 1968; lqbal et al., 2014) and weight ranged from $18-20 \mathrm{mg}$ (Akhdar, 2008). In our experiments, a long exposure to Habronema eggs in horse faeces (groups D0, D1) resulted in an average pupal length of $5.8 \mathrm{~mm}$. The average weight of these pupae was $16 \mathrm{mg}$. Pupae in the uninfected control group (KO) larvae of which were reared on a wet wheat bran-alfalfa mixture measured $7.1 \mathrm{~mm}$ and were $26 \mathrm{mg}$ massy.

As it was demonstrated in previous experiments (Schuster \& Sivakumar, 2016) already $1^{\text {st }}$ stage larvae that were removed on the second day from infectious horse faeces became infected. The prevalence of Habronema larvae in adult flies of this group was 48.6 with an average intensity of 3.6. Flies from larvae that were removed on the $3^{\text {rd }}$ day showed already a prevalence of $86.7 \%$ with an average intensity of 4.2. The average number of Habronema larvae rose to 26.6 in the group where larvae were removed prior to pupation at their $9^{\text {th }}$ day of life. Further stay in horse faeces did not increase the parasite burden since larvae had stopped consuming food. These trials showed that Habronema larvae are accumulated in fly maggots the longer these maggots were raised on substrates containing infective eggs.

In the current experiments we chose the opposite approach by putting immature fly development stages from larval rearing medium on infective horse faeces. This resulted in $100 \%$ prevalence and high larval burdens in adult flies in the groups D0, D1, D2, D3, D4 and D5 and rapidly decreasing prevalence and larval burdens 
Table 4. Prevalence and intensity of Habronema muscae in experimentally infected Musca domestica.

\begin{tabular}{lcccccc}
\hline Group & $\begin{array}{c}\text { Flies } \\
\text { examined }\end{array}$ & $\begin{array}{c}\text { Flies } \\
\text { infected }\end{array}$ & $\begin{array}{c}\text { Prevalence } \\
(\%)\end{array}$ & Average & Lower C.I. & Upper C.I. \\
\cline { 5 - 7 } D0 & 37 & 37 & 100.0 & 29.7 & 27.5 & 32.2 \\
D1 & 38 & 38 & 100.0 & 28.3 & 24.2 & 32.6 \\
D2 & 24 & 24 & 100.0 & 29.0 & 25.9 & 32.0 \\
D3 & 24 & 24 & 100.0 & 27.3 & 23.6 & 30.7 \\
D4 & 25 & 25 & 100.0 & 28.1 & 25.7 & 30.2 \\
D5 & 36 & 36 & 100.0 & 25.3 & 22.3 & 28.4 \\
D6 & 30 & 30 & 100.0 & 19.7 & 16.4 & 23.2 \\
D7 & 41 & 37 & 90.2 & 3.2 & 2.6 & 4.2 \\
D8 & 40 & 20 & 50.0 & 3.4 & 2.4 & 4.8 \\
D9 & 37 & 5 & 13.5 & 2.0 & 2.0 & 3.6 \\
D10 & 41 & 1 & 2.4 & 2.0 & - \\
\hline
\end{tabular}

in the remaining groups were growing maggots had only limited contact to the nematode eggs.

However, high nematode larval burdens in those groups with long exposure seem to be only the tip of the iceberg. The significantly lower pupation rate suggests that a large proportion of fly larvae died prior to pupation and subsequently caused a higher total mortality rate in preimaginal development stages while the pupal hatching rate was less influenced by the exposure.

Following ingestion, liberated $H$. muscae ${ }^{1 \text { st }}$ stage larvae penetrate the intestinal wall of the maggot causing multiple insults to this tube and allowing microbes to enter the coelom of the maggot. After a short stay in the coelom nematode larvae enter the cells of the adipose tissue leading to cellular necrosis. It is unknown however, which of these events has a bigger impact on infected maggots.

It seems that due to the loss of energy storage capacity, heavily infected fly larvae started to pupate earlier compared to the uninfected control.

The loss of parasitized adipose cells and the deficit of stored energy might be a simple explanation for smaller pupal size and weight of pupae and might be the reason for lower pupal and higher preimaginal mortality rates in experimental groups with long exposure to Habronema eggs. The deficit of hexamerin like proteins that are accumulated in the larval adipose tissues prior to pupation might have also contributed to the low total development rate of fly imagines since insect hexamerin plays a role in hormone binding and is involved in cuticle formation (Burmeister \& Scheller, 1997, 1999).

\section{References}

Akhtar, M. (2008): Public health aspects of the housefly Musca domestica L. (Diptera: Muscidae) - Enterococcus sp. association. PhD thesis, USA, Manhatten, Kansas State University Burmeister, T., Scheller, K. (1997): Conservation of hexamerin endocytosis in Diptera. Eur. J. Biochem., 244: 713 - 720. DOI: 10.1111/j.1432-1033.1997.00713.x

HEWITT, C.G. (1910): The house fly Musca domestica, Linnaeus. A study of its structure, development, bionomics and economy. Manchester, UK, At the University Press. 195 pp.

HILL, G.F. (1918): Relationship of insects to parasitic diseases in stock. Part 1: The life history of Habronema muscae, $H$. microstoma and $H$. megastoma. Proc. Roy. Soc. Victoria., 31: $11-76$

HowARD, L.O. (1898): Further notes on the house-fly. Some miscellaneous results of the work of the division of entomology. US Dept. Agric., Div. Entomol. Bull., 10: 63 - 65

Iqbal, W., Malik, M.F., Sarwar, M.K., Azam, I., IRam, N., Rashda, A. (2014): Role of housefly (Musca domestica, Diptera; Muscidae) as a disease vector; a review. J. Entomol. Zool. Stud., 2: 159 - 163 Johnston, T.H. (1913): Notes on some entozoans. Proc. Roy. Soc. Queensland, 24: 63 - 91

JOHnston, T.H., BANCROFT, M.J. (1920): The life history of Habronema in relation to Musca domestica and native flies in Queensland. Proc. Roy. Soc. Queensland, 32: 61 - 88

KaRANDIKAR, K.R., RANADE, D.R. (1965): Studies on the pupation of Musca domestica Nebulo Fabr. (Diptera-Cyclorrhapha-Muscidae). Proc. Ind. Acad. Sci., Section B, 61 (4): 204 - 213. DOI: 10.1007/BF03051009

Larrain, P., Salas, C. (2008): Housefly (Musca domestica L.) (Diptera: Muscidae) development in different types of manure. Chil. J. Agricult. Res., 68: 192 - 197. DOI: 10.4067/S071858392008000200009

LEIKINA, L.I. (1943): The role of various substrates in the breeding of Musca domestica. Med. Parasitol. (11): 82 - 86 (In Russian) MACHTINGER, E. (2011): Studies on the field ecology, breeding biology and parasitism of house flies, Musca domestica and stable flies, Stomoxys calcitrans, (Diptera: Muscidae) to improve integrated pest management for North Florida small equestrian farms. MSc Thesis, USA, Gainesville, University of Florida. 190 pp. 
Ransom, B.H. (1911): The life history of a parasitic nematode Habronema muscae. Science, 34: 690 - 692

Roubaud, E., Descazeaux, J. (1921): Contribution a l'histoire de la mouche domestique comme agent vecteur des habronemoses d'equides. Cycle evolutiv et parasitisme de l' Habronema megastoma (Rudolphi, 1819) chez la mouche [Contribution to the knowledge of the housefly as vector of equine habronemoses. Life cycle and parasitism of Habronema megastoma (Rudolphi, 1819) in the fly]. Bull. Soc Pathol. Exot. 14: 471 - 506 (In French)

Roubaud, E. Descazeaux, J. (1922): Evolution de I' Habronema muscae Carter chez la mouche domestique et de l' $H$. microstoma Schneider chez le stomoxe [Development of Habronema muscae Carter in the housefly and $\mathrm{H}$. microstoma Schneider in the stable fly]. Bull. Soc. Pathol. Exot. 15: 471 - 506 (In French)

Rozsa, L., Reiczigel, J., Majoros, G. (2000): Quantifying para- sites in samples of hosts. J. Parasitol. 86: 228 - 232. DOI: 10.1645/0022-3395(2000)086[0228:QPISOH]2.0.CO;2

SCHUSTER, R.K., SivAKUMAR, S. (2013): A xenodiagnostic method using Musca domestica for diagnosing gastric habronemosis and examining the anthelmintic efficacy of moxidectin. Vet. Parasitol., 197 (2013) 176 - 181. DOI 10.1016/j.vetpar.2013.06.015

Schuster, R.K., SivakumaR, S. (2017): The larval development of Habronema muscae affects its intermediate host, Musca domestica. Parasitol. Res., 116: 503 - 509. DOI 10.1007/s00436-0165312-y

SKIDMORE, P. (1985): The biology of the Muscidae of the world. UK, Lancaster, Kluwer Academic Publishers, 550 p.

ZUMPT, F. (1968): Myiasis in man and animals in the world. UK, London. Butterworth, 267 pp. 